\title{
A quien fue un verdadero maestro: Aquiles Montoya
}

Gladys Cañas, Diana Castro, Nathalie Chacón, Adonay De Paz y Marielos García

\section{Introducción}

- n este breve artículo queremos plasmar, con un tono más personal - que académico, algunas ideas de nuestro recordado y muy apreciado maestro Aquiles Montoya, que influyeron en nuestro pensamiento económico, a través de sus magistrales cátedras, excelentes libros y artículos.

Sus clases sembraron las semillas de un pensamiento crítico y la esperanza que se puede modificar la situación de este país, plagado de injusticias y desigualdades, a través de la creación de relaciones de poder populares, como un medio para cambiar el capitalismo. De esta forma, para crear otro sistema no basta con un nuevo gobierno, aunque sea de izquierda; ya que los sistemas jurídico y político están diseñados, de tal manera, que se busca la reproducción del modo de producción imperante.

En la primera parte, presentamos algunas ideas relacionadas con su labor docente; en la segunda y tercera, dos elementos de su pensamiento teórico: la crítica al capitalismo y la economía solidaria, respectivamente.

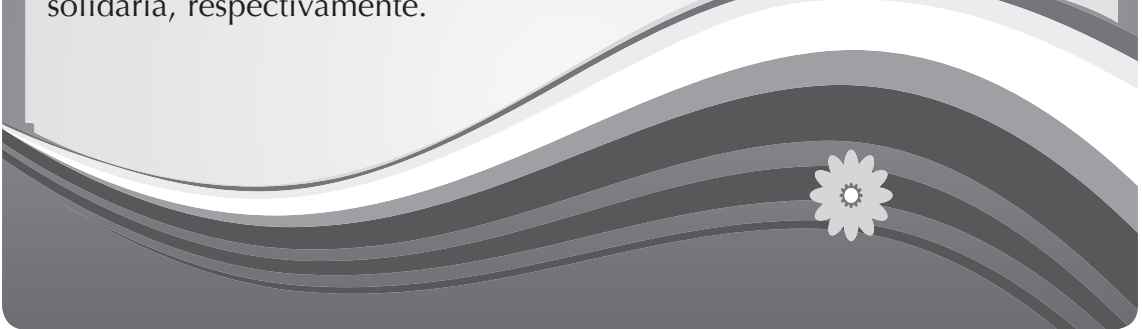


Por último, en las reflexiones finales recordamos su llamado a la juventud a formarse y a creer en un cambio. También, como parte de las reflexiones finales, se presenta una crítica a la racionalidad costo- beneficio, que invade las diferentes esferas de la vida; por ejemplo cuando se "valora" a una persona en cuanto que es "productiva" o representa "menores costos".

\section{El inmortalizado maestro en nuestros recuerdos, quien murió como vivió}

El maestro Montoya con su jovialidad, idealismo, objetividad, gran cúmulo de conocimientos, espíritu crítico, franqueza y honestidad —intelectual y personal- se preocupó por inspirarnos el amor y estima por el conocimiento, además de una mentalidad crítica. Creía en el cambio del sistema económico -el capitalismo- y pensaba que las personas no éramos egoístas por naturaleza, sino solidarias. Así, expresaba:

"la experiencia empírica está demostrando que las personas no son individualistas, egoístas, ni envidiosas por naturaleza. Tales prácticas tienen una determinación social y no natural. Es el capitalismo el que promueve y fomenta tales antivalores y sin embargo, en las comunidades organizadas se vive la cooperación, la unidad y la solidaridad" (Montoya. 2009:78).

Con una posición revolucionaria frente al capitalismo y la convicción de que los seres humanos pueden ser agentes de cambio, transmitió un pensamiento crítico que, como estudiantes de economía, a una parte, nos llevó a identificar a la carrera como un medio de transformación de la realidad.
De la misma forma, brindó una alternativa de pensamiento $y$ análisis respecto a la teoría neoclásica orientada por la racionalidad medio-fin y la eficiencia económica; que se abstrae, en nombre de la cientificidad, de la racionalidad reproductiva.

\section{Recuadro 1. Desde la memoria y el corazón de los estudiantes}

Recuerdo la frase con la que inició la primera clase que recibí con el maestro Aquiles: "dicen que yo les lavo el cerebro a lo cipotes y es cierto, pues la traen sucia de capitalismo", diciéndolo de forma directa y clara como acostumbraba a expresar las cosas. Así dio inicio a un 
proceso de desmitificación de la realidad, como lo manifestaba muy a menudo. Siempre intentó transmitir, a cada estudiante, su experiencia y conocimientos, muy consciente de que no todos compartían su visión y por tal razón no todos estarían de acuerdo con sus ideas, así mencionaba: "Yo les doy las herramientas (sus conocimientos), pero ustedes deciden qué hacer con ellas".

Sus ideas influyeron mucho en lo que para mí es economía, de esta manera, me enseñó que el ser humano no puede reducirse a una cuestión de números; pues a pesar de ser la principal fuerza productiva de la sociedad, por su condición humana, sus necesidades no se limitan a alimentarse y sobrevivir. En otras palabras, las personas no solo tienen necesidades físicas, sino que también espirituales para su reproducción.

Sus ideas me hicieron ver que aunque la economía mundial está regida principalmente por un sistema capitalista injusto, opresor y desigual, aún existe la esperanza de lograr una sociedad más justa y equitativa a través de la solidaridad, un valor con el que siempre se identificó y que plasmó en su teoría o utopía, como él llamó a la economía solidaria.

Su aporte a la economía fue inmenso, importantes libros, estudios y análisis de la realidad, pero uno de los más grandes fue la transmisión del mensaje que una sociedad solidaria es posible.

Manfredy Barahona (Estudiante de quinto año de la Licenciatura en Economía).

Se muestra, entonces, el interés del maestro Aquiles por formar, más que intelectuales, a seres transformadores de su realidad. Este interés por el aprendizaje se caracterizaba por motivar a sus alumnos a ser capaces de asimilar, relacionar y contextualizar las ideas adquiridas hasta el punto de crear un pensamiento propio.

Como bien lo expresó Dagoberto Gutiérrez, el 29 de enero del presente año, antes de partir hacia el cementerio de San José Villanueva: no todos los profesores son maestros. Es largo y arduo el camino para llegar a serlo. El maestro Montoya se convirtió en uno, y uno grande e invaluable, al incentivar a sus estudiantes a pensar críticamente, a relacionar la teoría con la realidad, a generar una cultura contestaría abierta al debate, a ser propositivos y creativos en la búsqueda de soluciones a los problemas que adolece nuestra sociedad. 
Fue así como el profesor Montoya nos devolvió la esperanza de que la economía sí puede servir para generar un cambio social. Con sus enseñanzas marxistas, de forma clara y convincente nos llevó por el camino de la reflexión sobre el funcionamiento del modo de producción capitalista y su cambio a través de una economía que no se basa en el individualismo, ni el atomismo social, sino que tiene como valor fundamental la solidaridad.

Lo anterior nos hace afimar que el maestro Aquiles cumplió el ideal de docencia que tenía el padre Ignacio Ellacuría, -por quien manifestaba sentir una gran admiración-, que plasma en sus Escritos Universitarios (1999). Este arquetipo de docencia se refiere a que esta debe buscar ser óptima desde el punto de vista técnico y ético; convirtiéndose así en un instrumento para transmitir conocimiento y valoraciones, en la medida que esté orientada por la proyección social y hacia la realidad nacional.

Nuestro maestro Aquiles Ilegaba al salón de clases no solo a exponer conceptos aprendidos en los libros; sus cátedras estaban impregnadas de la realidad nacional y como cuando una aguja revienta un globo, nos hacía darnos cuenta de las burbujas en las que vivíamos muchos de sus alumnos. Al final de su curso decía "el que recibe clases conmigo se va baleado" y nos reíamos incapaces de negarlo, ya que tocó las conciencias de todos, nos abrió los ojos y nos hizo ver la injusticia, la desigualdad, la explotación, la sobrexplotación y la exclusión que genera este sistema.

El padre Ellacuría planteaba que al docente debe exigírsele "una óptima preparación para enseñar aquello que convierta al país en algo mejor (...) debe estar bien preparado técnica y éticamente para contribuir al bien global de la sociedad" (Ellacuría, 1999: 137). Asimismo, expresaba que "para estar en condición de transmitir los valores humanos y éticos específicos, es preciso que los docentes estén identificados con ellos" (Ellacuría, 1999: 142).

Así lo hizo el profesor Montoya, ya que su cátedra reflejaba el cúmulo de conocimiento que poseía, su facilidad de exposición siempre capturaba la atención de sus alumnos, transmitiéndonos aquellos valores en los que firmemente creía "la solidaridad y el humanismo- y que plasmó en su teoría "economía solidaria-. La cual no fue si no el fruto de una retroalimentación con la realidad, un afectar y dejarse afectar por el entorno y las personas.

La capacidad de mostrarse como un hombre conocedor del campo y la ciudad, servía de inspiración para muchos. El maestro fue capaz de traer a la mente de los alumnos de la UCA un mundo rural y su idiosincrasia, descono- 
cido para muchos y muy conocida para otros. De esta manera, cumplía con lo que decía el padre Ellacuria (1999): "La docencia ( ) supone un contacto con diversas personas que traen diversos trasfondos culturales, sociales, económicos e ideológicos, todo lo cual puede enriquecer la experiencia del docente".

Nuestro maestro supo enriquecer y enriquecerse de sus alumnos; con sus vivencias de la infancia y sus anécdotas en las comunidades con esfuerzos de economías solidarias; así dejaba ver su profundo respeto y admiración por la honestidad, solidaridad y creatividad que poseen los seres humanos.

Sin duda alguna, Aquiles Montoya se caracterizó por ser un verdadero maestro, que enseñó no solo haciendo uso de sus palabras, sino que iba más allá y nos permitía aprender de sus acciones. Esto fue posible, gracias a que sus actos estaban en concordancia con sus ideas. Con un estilo de vida y trabajo que mostraba la pura vivencia de su pensamiento, tal como lo describe Roque Dalton: "El hombre debe ser una totalidad en teoría y acción. Su concepto del mundo, sus normas más abstractas en las que cree deben enmarcar su conducta, deben corresponder a su posición y a sus manifestaciones ante el mundo" (Dalton, 1956).

El maestro Aquiles Montoya no restringía la fuerza de su pen- samiento al mero conocimiento, sino que actuaba con base en ello. Esto motivaba a los demás no solo a cultivar el intelecto, sino también inspiraba y transmitía el deseo de actuar y llevar a la realidad aquellas ideas que más que ser económicas se caracterizaban por ser humanas, retomando así, el sentido humano de la economía.

Dalton (1956) planteaba que "para ser una totalidad de hombre, se precisa el equilibrio, la correspondencia entre lo que se piensa y lo que se hace, entre lo que se pregona y realiza", esto es un escritor comprometido como Aquiles Montoya demostró ser a lo largo de sus días, una totalidad de hombre y como él mismo lo manifestaba con una de sus frases en clase: "Hay que actuar como se piensa, porque si no se termina pensando como se actúa".

Una de las grandes lecciones que nos dejó el maestro Montoya cuando fuimos sus alumnas y alumnos, es a estar en contra del sistema económico, a pesar de los beneficios que este pueda proporcionar. Él declaraba, sin ningún tipo de ambigüedad y con la firmeza que lo caracterizaba: "También por esto soy anticapitalista. Estoy por la vida, no por la mera existencia, por muy cómoda que pueda ser" (Montoya, 2010g).

Según sus planteamientos, existe el imperativo categórico de aca- 
bar con el capitalismo, ya que no es posible que este garantice "la reproducción material y espiritual de la mayoría de la población mundial" (Montoya, 2011:1).

\section{Algunas críticas al capitalismo}

Para el maestro Montoya el sistema capitalista está a la base de cualquier problema económico, social, cultural, político, jurídico, ideológico o ecológico. En él la clase capitalista busca por diferentes medios maximizar la producción, realización y apropiación de plusvalía, con lo que muestran la mayor paradoja del sistema: búsqueda de la maximización de ganancias.

El sistema capitalista es un sistema inviable y posee la característica de presentar la realidad de forma mistificada, ya que la apariencia prevalece sobre la esencia. En las palabras del maestro "una característica importante del sistema es el enmascaramiento, la metamorfosis de la realidad o la fetichización de la misma, lo cual se encuentra en la raíz del sistema mercantil capitalista" (Montoya, 2010g).

En el capitalismo, a los objetos se le atribuyen cualidades que de suyo no poseen. Así, se ha llegado al fetichismo de las marcas, del capital y de las riquezas materiales, transformando la humanidad y separándola de los principios y valores que la deberían caracterizar. En otras palabras:

\section{"Desde el momento en que consideramos a los productos del trabajo humano como mercancías, como valores, y no como simples objetos útiles, se desencadena toda una gama de fetiches que nos dominan, que nos esclavizan y que nos llevan a necesitarlos y a quererlos "como el adicto quiere la droga- y a hacer todo aquello que sea necesario para tener- los. Así es el capitalismo, así funciona" (Montoya, 2010g).}

El fetichismo mercantil, descrito anteriormente, no puede ser eliminado a través de ninguna vía que no sea el cambio de las relaciones sociales que le dieron origen y que son propias del sistema capitalista. Los hábitos de vida, de trabajo, sueños, anhelos y principios terminan siendo condicionados al mistificar la realidad, por lo que es inevitable ser anticapitalista y es imperioso darle respuesta a los problemas derivados de esta situación.

Por ello propone una visión auténtica de desarrollo que dé respuesta a tres tipos de problemas, los cuales son: los males propios del 
sistema, los problemas ambientales y la cultura patriarcal. Estos se explican, brevemente, a continuación.

\subsection{Males propios del sistema}

Actualmente, nos encontramos ante lo que para una parte de las personas se denomina el fin del sistema capitalista, debido a los múltiples males sociales, económicos y políticos que a raíz, de sus principios y racionalidad, se han generado. Entre esos males (ver figura 1) se encuentran:

a. La concentración y centralización del capital. La concentración se da a través de la reinversión de la plusvalía, es decir cuando parte de esta se destina a un nuevo proceso de producción y la otra es consumida por el capitalista. En cambio, la centralización se refiere a la distribución de capitales que ya existen y que puede encontrarse "en manos" de unos pocos.

Así, la concentración y centralización del capital tienen como consecuencia la concentración y centralización del ingreso, debido a que unos pocos se apropian de un alto porcentaje del ingreso, mientras que la mayor parte se apropia del porcentaje más bajo.

b. La pobreza de una parte considerable de la población. Esta tiene como principales causas: el desempleo, el subempleo y los bajos salarios. En el caso específico de El Salvador, según la Encuesta de Hogares de Propósitos Múltiples, en 2010 el nivel de pobreza alcanzaba el $36.5 \%$, acompañado de un elevado porcentaje de subempleo $(28.9 \%)$ y desempleo (7.1\%). Así como de un ingreso promedio mensual de $\$ 479$, que refleja la incapacidad del sistema capitalista por brindar un empleo digno a los sectores de la sociedad que no son poseedores de medios de producción (EHPM, 2010).

Como antes se mencionó estas situaciones generan pobreza en la población, es decir insatisfacción de necesidades básicas: alimentación, educación, vivienda, agua, etc. Además estos conflictos se ven agudizados por las consecuencias que conlleva ser un país dependiente económica, política y culturalmente. 
Figura 1. Males del capitalismo

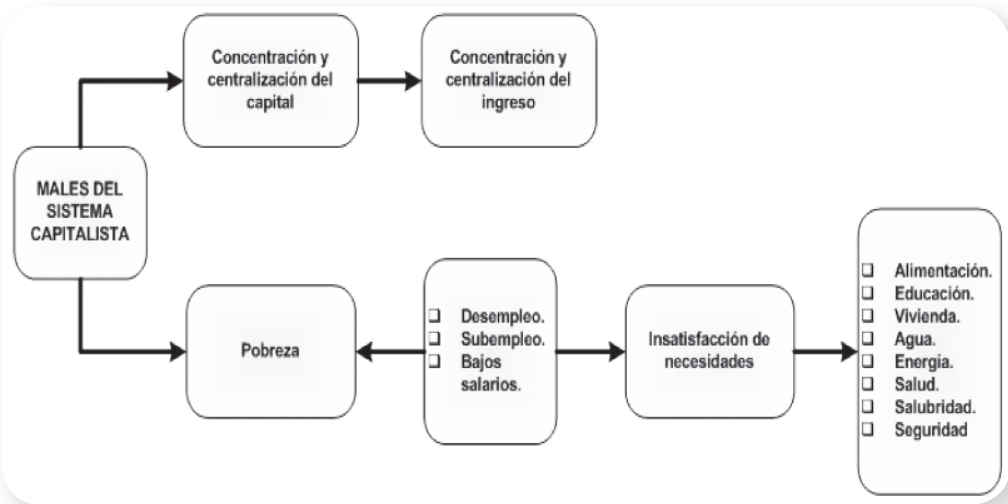

Fuente: Clases de Introducción a las teorías del desarrollo. Aquiles Montoya, 2010.

\subsection{Problemas ambientales}

Debido a la búsqueda incesante de beneficios por parte de los propietarios de los medios de producción se ha producido un grave problema ambiental (ver figura 2).
De esta manera, la construcción de edificios, carreteras, zonas habitacionales, etc. ha traído consigo el agotamiento de los recursos, la contaminación de aire, agua y suelo. Si esto no cambia, iremos a un "suicidio colectivo".

\section{Figura 2. Fuente de los problemas ecológicos}

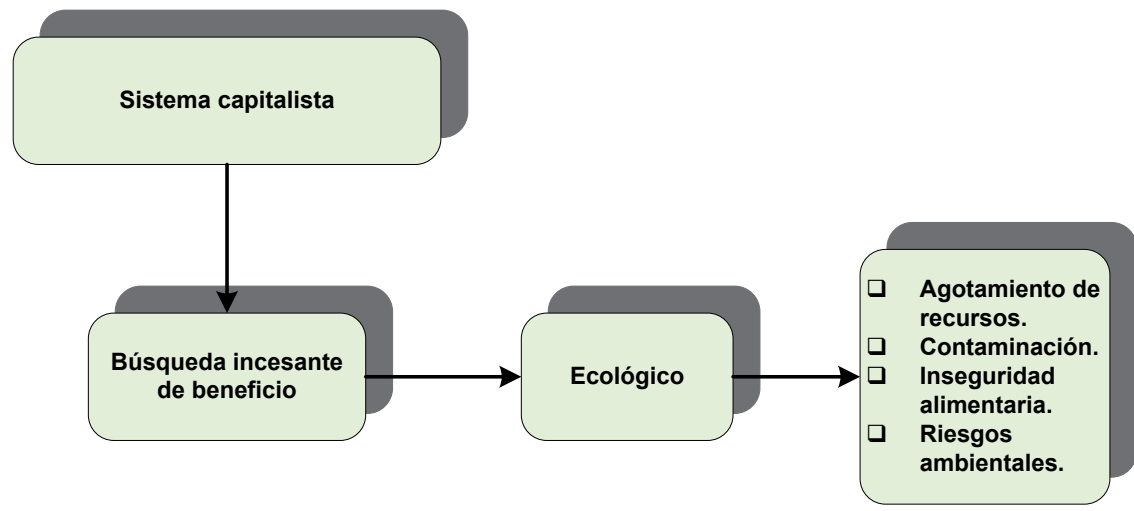

Fuente: Clases de Introducción a las teorías del desarrollo. Aquiles Montoya, 2010. 


\subsection{Cultura patriarcal}

Si bien es cierto que la cultura patriarcal no surge con el capitalismo, este la perpetúa y reproduce porque sirve para sus intereses (ver figura 3). Por ejemplo, el trabajo doméstico no remunerado que realizan, en mayor medida, las mujeres es producción para autoconsumo y no implica relaciones salariales. Lo que permite una reproducción parcial de la fuerza de trabajo para el capital; sin embargo al no ser remunerado permite a los capitalistas ahorrar ese costo, lo que conlleva a una plusvalía extraordinaria.

\section{Figura 3. Reproducción y perpetuación de la cultura patriarcal por el capitalismo}

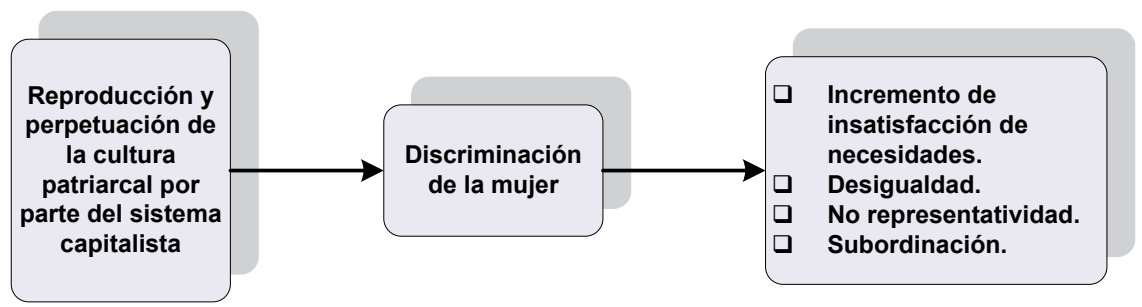

Fuente: Elaboración propia con base en Montoya (2010) y Montoya (2010d).

Para el maestro Montoya (2010d), el patriarcado es una relación de dominio-subordinación que cobra una dimensión social de poder del hombre sobre la mujer y se expresa en situaciones con las que ella debe luchar día a día, tales como: la discriminación y menor representatividad en ámbitos como los sociales, políticos, económicos, culturales y familiares; la desigualdad; las diferenciaciones salariales por el simple hecho de ser mujer; la violencia intrafamiliar; el acoso sexual; su cosificación hasta el punto de ser considerada, en muchos casos, como un objeto sexual; entre otros.
Ante esta problemática, el maestro Montoya, dio énfasis a los avances que se han realizado a lo largo de la historia, uno de ellos es la incorporación de la mujer al mercado laboral; lo cual le brinda oportunidades de educarse y vincularse en las actividades políticas y sociales. Esto va de la mano con una cierta autonomía económica que contribuye a generar las condiciones para que la mujer tome conciencia de su condición en la cultura patriarcal (Montoya, 2010d).

Destaca, también, la labor organizativa y formativa de los movimientos feministas, en el proceso 
de empoderamiento de la mujer; el cual se refiere a la capacidad de las mujeres de exigir sus derechos y de resistir las exigencias de una sociedad machista, adquiriendo la capacidad necesaria para cambiar la cultura del patriarcado (Montoya, 2010d).

De esta manera, son necesarios estos y más esfuerzos para lograr una sociedad en la que no se viva el predominio del hombre sobre la mujer, tomando en cuenta que el sistema educativo actual, el hogar, la religión, los medios de comunicación y la sociedad en general reproducen este sistema.

En este sentido, el maestro Aquiles expresa que "el proceso de cambio de la cultura patriarcal no puede reducirse a la educación en la niñez, en la pubertad o la edad adulta, tanto de uno como de otro sexo, exige de la praxis, praxis que debe implementarse en todos los ámbitos de la actividad humana" (Montoya, 2010d).

Para Aquiles Montoya (2009) las causas de los tres problemas antes mencionados: los males propios del sistema, problemas ambientales y la cultura patriarcal tienen como base al sistema capitalista; por tanto, para que sean solucionados es necesario que este sistema sea transformado en toda su estructura, funcionamiento y racionalidad. Cualquier medida que se implemente, por muy bien intencionada que sea, no podrá enfrentar el desempleo, la situación de pobreza, exclusión social, y ya no se diga la degradación ambiental y la desigualdad de género, esto debido a que se ve frenada en la práctica por los límites que el sistema mismo impone.

Por lo tanto, al conocer las contradicciones propias del sistema y todos los males que ocasiona, se debe buscar una alternativa que genere una sociedad distinta. El maestro Aquiles planteaba que es posible una "sociedad mejor" cuyo fundamento sea el trabajo, la organización y la solidaridad. Su lógica de funcionamiento será totalmente distinta a la del capitalismo, pues la búsqueda del excedente no es un fin en sí mismo, el trabajo es un medio de realización humana e implica procesos productivos que preserven la naturaleza. Esto se logrará a través de la creación de empresas solidarias que lleguen a formar una economía solidaria.

Dicho planteamiento fue plasmado por el maestro Montoya tanto en sus escritos como en su cátedra, jamás olvidaremos cuando en la clase de economía solidaria -luego de haber preguntado a los alumnos por los problemas que veían en la realidad- con palabras muy del corazón decía: ante la injusticia, ante la opresión, ante la desigualdad de género, ante la explotación, ante la degradación ambiental, ante la pobreza, ante la exclusión y margi- 
nación, ¿será posible una sociedad distinta? Y con un prolongado sí, nos dijo, "Sí, ustedes son la esperanza".

\section{Algunas ideas relacionadas con la realidad y utopía de la economía solidaria}

La economía solidaria es la búsqueda teórica y práctica de hacer economía de manera alternativa, fundamentada en el trabajo y en la solidaridad. Se puede decir que es un modelo alternativo de y para las mayorías populares en los ámbitos políticos, económicos, sociales, culturales e ideológicos, fundamentado en su propio esfuerzo organizativo y solidario "que tiene como finalidad resolver sus problemas ambientales, de pobreza y exclusión social, tanto en el campo como en la ciudad y contribuir a la eliminación de las causas que la generan" (Montoya, 2009:35).

Así, se pueden mencionar las características siguientes:

a. Una racionalidad económica diferente. Con el fin de que se busque satisfacer las necesidades de las personas, tanto materiales como inmateriales (autoestima, realización personal, felicidad, solidaridad, igualdad).

b. Una economía ecológica y en la que no existan diferencias de género.

c. No debe existir la expoliación ni la explotación. Esto, con el objetivo de generar un cambio total de estructuras. Así, la social ya no sería clasista, es decir no estaría dividida por clases, lo cual llevaría a transformar la estructura ideológica, que a su vez se manifestaría en otra cultura que requiere de una organización jurídica, política, mediática y militar diferente.

Tal como el maestro Aquiles destaca en las características anteriores, la economía solidaria requiere de nuevas formas de conciencia social que necesariamente presuponen la conformación de una nueva sociedad, con formas de producción y de vida amigables con el medio ambiente, sin la relación de dominio del hombre sobre la mujer, etc.

Además el cambio sustancial y progresivo de la sociedad se debe manifestar en el ámbito de la producción, distribución, circulación y consumo. De esta forma, la distribución de la producción se da entre quienes la han generado y en cuanto que es solidaria incluye a quienes más lo necesitan. Por su parte, la circulación al ser solidaria evita el intercambio desigual, ya que los bienes se transan según la cantidad de trabajo requerida para su producción. El consumo solidario debe caracterizarse por ser austero, 
contrario al consumismo actual, para garantizar así bienes y servicios para la población existente, sin que esto implique la degradación del medio ambiente (Montoya, 2010c).

Como el maestro Aquiles lo expresaba en sus clases, en esta nueva sociedad no se supone la existencia de una estructura política porque, al no haber clases sociales ni patriarcado no se presentan relaciones de poder, ya que las relaciones sociales pasarían a ser solidarias. Asimismo, no permite la propiedad privada, y hace referencia a una situación de no propiedad.
Esta mejor forma de organización económico-social tiene como fundamento una cualidad humana que no ha sido destruida por el egoísmo imperante en el modo de producción capitalista: la solidaridad, por lo que la sociedad solidaria se constituye como la opuesta a la capitalista (Montoya, 2010h).

Así, para que sea posible el funcionamiento y permanencia en el tiempo de la economía solidaria, se requiere que se fundamenten determinados principios y valores (ver cuadro 1), tales como la honestidad, espíritu de lucha, cooperación, unidad, entre otros.

\section{Cuadro 1. Valores y principios de la economía solidaria}

\begin{tabular}{|c|c|}
\hline Valores & Principos \\
\hline Solidaridad & Honestidad \\
\hline Cooperación & Espíritu de lucha \\
\hline Equidad & $\begin{array}{ll}\text { Toma } & \text { de } \\
\text { desiciones } & \text { de } \\
\text { manera } & \\
\text { participativa } & \end{array}$ \\
\hline Unidad & $\begin{array}{l}\text { Educación } \\
\text { permanente }\end{array}$ \\
\hline Autonomía & $\begin{array}{l}\text { Membresía abierta } \\
\text { y voluntaria }\end{array}$ \\
\hline Autogestión & \multirow{2}{*}{$\begin{array}{l}\text { Unidad en la } \\
\text { diversidad }\end{array}$} \\
\hline Eficiencia & \\
\hline
\end{tabular}

Fuente: Clases de Economía Solidaria. Aquiles Montoya, 2010.

A modo de conclusión de este apartado, se puede afirmar que la economía solidaria pretende ser el fundamento de la sociedad solidaria (utopía), donde no existen las clases explotadoras, ni la propiedad, ni el 
poder. De esta manera, para que esta sea posible se debe buscar la adhesión de personas que comprendan las causas últimas de los grandes problemas que genera el capitalismo. Así, la transformación debe ser desde la base, es decir, la transformación debe venir de las personas afines a esta.

\section{Reflexiones finales}

El 27 de enero de este año murió el maestro Aquiles, a sus 68 años de edad, de los cuales los últimos treinta los dedicó a la docencia y a la investigación en la UCA, dejando en su largo andar a varias generaciones de estudiantes que pasaron por sus clases, que sintieron la frescura de su saber y la fuerza de sus enseñanzas. Una parte de nosotros tuvo el privilegio de verlo en sus últimas clases y aunque su rostro reflejaba las arrugas que su intensa vida le había dado, su pensamiento era como agua fresca y a la vez torrencial, que hacía vibrar nuestros corazones, con esa esperanza que solo da una persona llena de ideales y sueños, que perseguía su utopía; tal y como nos dijo: "yo, que estoy viejo, tengo sueños e ideales, ¿cómo no van a tenerlos ustedes, que son jóvenes?".

El maestro Aquiles es el vivo ejemplo de que mantenerse joven está en la capacidad y necesidad de seguir aprendiendo, en su entusiasmo, perseverancia y lealtad a sus ideales; que no se caracterizaban por ser egoístas, sino todo lo contrario, sus ideales respondían a las necesidades sociales. Tal como Beauvoir (1997) lo expresa: "con- servar vitalidad, alegría, presencia de espíritu, es permanecer joven".

Gran claridad de ideas, amplio conocimiento y capacidad analítica mostraba el maestro Aquiles Montoya en sus clases, en sus artículos, en sus libros y en su diario vivir, haciendo constar que la edad no es un obstáculo; sino más bien, una fase de desarrollo tal, que permite aportar ideas nuevas e innovadoras, se habla con el respaldo de las experiencias, se vinculan los conocimientos adquiridos y la capacidad creativa es ilimitada, ya que se poseen las herramientas suficientes para hacer aportes de gran valor teórico y práctico a la ciencia y a la sociedad.

Pero las apreciaciones sociales hacia a las personas mayores no siempre han estado orientadas hacia la valoración y admiración de la sabiduría que ellas pueden proporcionarnos; es decir, la situación que viven las personas de la tercera edad ha sido distinta en cada sociedad y época. En algunas efectivamente se les valoraba, tal como pasó en las culturas primitivas de la historia de la humanidad, en la que la vejez era sinónimo de 
sabiduría y era un privilegio llegar a edades avanzadas; también, para los hebreos en la etapa nómada, los ancianos eran los líderes.

Actualmente, parecería que las personas mayores no son tomadas en cuenta a pesar de su vasta experiencia y conocimiento. Es más se deja de lado que al motivarlos y hasta cierta medida presionarlos a retirarse del sistema de producción, en una sociedad que se caracteriza por las relaciones de producción. Lo que lleva a la mortalidad aumente, independientemente de la situación socioeconómica que posean.

De esta manera, Simone de Beauvoir en La edad de la discreción (1997) muestra cómo las personas de mayor edad luchan ante la influencia social que los motiva a percibirse a sí mismas con falta de creatividad, energía y potencial. La sociedad que describe tácitamente Beauvoir no es distinta de la contemporánea, pero ipor qué no considerar a las personas mayores como una fuente de conocimiento? ¿Por qué privarse de la posibilidad de enriquecerse con la experiencia, las vivencias y el cúmulo de conocimientos que las personas mayores pueden aportarnos?
Aquiles Montoya fue un ejemplo de que aunque el cuerpo envejece, el corazón conserva la vitalidad, auxiliado por un espíritu incansable y una mente abierta al conocimiento. Hasta en las últimas horas de su vida, nos motivaba a ser personas de mente joven, para cambiar de enfoque cuando fuera necesario, ya que la realidad es cambiante, no estática; por tanto, nuestro pensamiento, ideas del mundo, tampoco lo deben ser. Así, mantenerse de mente joven implica la capacidad de permitir la evolución de conocimiento propio y de una mejora continua.

Con una mirada firme, una forma de expresarse a veces sarcástica, de vez en cuando pícara, la cátedra fluía entre preguntas y reflexiones, chistes y ocurrencias del maestro, algunos regaños "los veo muy pasivos chicos, me gustan los alumnos que no se quedan callados, que no se creen todo lo que el profesor dice" y de cuando en cuando planteaba palabras profundamente inspiradoras, como las que nos dejó plasmadas en su artículo titulado "¿Usted que piensa?" publicado en Contrapunto:

"Nuestra juventud, debería dedicar más tiempo a leer que
a ver tele, eso no sólo les enriquecería su lenguaje, sino que
les daría cultura, no sólo literaria, sino histórica, científica,
geográfica, etc. Y además, aprenderían a pensar y a escri-
bir con lógica. En la actualidad con el acceso que existe a
múltiples fuentes de conocimiento, vía internet, no existe A quien fue un verdadero maestro: Aquiles Montoya 
excusa para no formarse. Jóvenes, dediquen por lo menos dos horas diarias a leer, al menos, periódicos alternativos ( ) Háganse un favor, abran su mente al mundo, infórmense, cultívense. La diferencia de los humanos con los animales es que no sólo comemos, dormimos y nos reproducimos, sino que pensamos, tenemos necesidades de carácter espiritual, esas que nos brindan la cultura y el saber" (González, 2011:3).

Muchos leímos con gran pesar su último artículo, publicado en vida (a escasas horas de su muerte), en el periódico digital Contrapunto titulado La importancia de poseer una mente abierta, el cual finaliza con una fraternal frase de despedida: "Adiós muchachos, los quiero mucho, pero por favor cultívense!"

No dudamos que esta frase calará hondo en los corazones de quienes fuimos sus alumnos, compañeros, amigos, seguidores o lectores. Asimismo, implica un desafío para la juventud de cultivarse, prepararse y buscar alternativas a un sistema opresor, injusto y desigual. Su muerte conlleva el compromiso de seguir con su pensamiento solidario, de luchar con vigor como lo hizo nuestro maestro en vida, contra la ignorancia, contra la indife-

\section{BibliografíA}

Beauvoir, S., (1997) La edad de la discreción. Edición número 22. Buenos Aires.

Dalton, R., (1956) "El poeta es una conducta" en Sábados de Dia- rencia hacia la realidad que aqueja a nuestra población y en contra de un sistema capitalista que pone en peligro la existencia humana.

Para todos aquellos que queramos honrar quien fuera en vida, es imperante indagar incesantemente en el conocimiento de la realidad del país, tener una mentalidad joven y creativa, pero ante todo tener una responsabilidad como profesionales o futuros profesionales, de buscar el bienestar de la sociedad, como él lo hizo con su legado teórico, al poner en el centro de su pensamiento al ser humano.

Hasta pronto muy extrañado y querido maestro, lo mejor que podemos hacer para honrar su recuerdo, es continuar con su legado.

rio Latino. 29 de septiembre de 1956.

DIGESTYC.(2010). "Encuesta de Hogares de Propósitos Múltiples". [En línea]. San Salvador, dispo- 
nible en: http://www.digestyc. gob.sv/index.php?option=com phocadownload \&view $=$ categ ory\&id=2: ehpm\&ltemid $=184$ [Consultado el 12 de febrero de 2012].

Ellacuría, I. (1999). Escritos universitarios. San Salvador, El Salvador: UCA Editores.

González, O., (2011) “¿Usted qué piensa?" en Contrapunto. 11 de diciembre de 2011. [En línea], disponible en: http://www.contrapunto.com.sv/colaboradores/ usted-que-piensa [Consultado el 3 de febrero de 2012].

Hinkelammert, F., (1996) El mapa del Emperador. Departamento Ecuménico de Investigaciones (DEI).

Montoya, A., (2009) "Sugerencias para enfrentar la exclusión social" en Portal de Economía Solidaria. 5 de Agosto de 2009. [En línea], disponible en: http:// www.economiasolidaria.org/ documentos/sugerencias_para_ enfrentar_la_exclusion_social [Consultado el 4 de febrero de 2012].

Montoya, A., (2010) Manual de Economía Solidaria. Maestría en desarrollo local. Universidad Centroamericana "José Simeón Cañas". El Salvador.
Montoya, A., (2010a) Apuntes de clase de Economía Solidaria. Abril 2010.

Montoya, A., (2010b) Apuntes de clase de Introducción a las Teorías del Desarrollo. Realidad Actual. Ciclo 01. Junio 2010.

Montoya, A., (2010c) "¿Qué es la economía solidaria?" en Contrapunto. 5 de Julio de 2010. [En línea], disponible en: http:// www.contrapunto.com.sv/coyuntura/que-es-la-economiasolidaria [Consultado el 6 de febrero de 2012].

Montoya, A., (2010d) "Mujeres y capitalismo" en Contrapunto. 6 de septiembre de 2010.[En línea], disponible en: http:// www.contrapunto.com.sv/colaboradores/mujeres-y-capitalismo [Consultado el 15 de febrero de 2012].

Montoya, A., (2010e) "¿Ser o no ser anticapitalista?" en Contrapunto. 5 de octubre de 2010. [En línea], disponible en: http://www.contrapunto.com. sv/colaboradores/ser-o-no-seranticapitalista [Consultado el 11 de febrero de 2012].

Montoya, A., (2010f) "¿Por qué soy anticapitalista?" en Contrapunto. 11 de octubre de 2010. [En línea], disponible en:http:// 
www.contrapunto.com.sv/Colaboradores/por-que-soy-anticapitalista [Consultado el 1 de febrero de 2012].

Montoya, A., (2010g) "Otras razones por las que soy anticapitalista" en Contrapunto. 14 de octubre de 2010. [En línea], disponible en: http://www.contrapunto.com.sv/colaboradores/ otras-razones-por-las-que-soyanticapitalista [Consultado el 1 de febrero de 2012].

Montoya, A., (2010h) "Ser anticapitalista iy entonces?" en Contrapunto. 22 de octubre de 2010. [En línea], disponible en: http:// www.contrapunto.com.sv/colaboradores/ser-anticapitalistay-entonces [Consultado el 1 de febrero de 2012].
Montoya, A., (2012a) El Manifiesto Solidario. Rebelión. 18 de enero de 2012. [En línea], disponible en: http://www.rebelion.org/noticia.php?id=143083 [Consultado el 11 de febrero de 2012].

Montoya, A. (2012b). "La importancia de poseer una mente abierta" en Contrapunto. 27 de Enero de 2012. [En línea], disponible en: http://www.contrapunto.com.sv/otros-temas/ aquiles-montoya-el-economistamarxista [Consultado el 11 de febrero de 2012].

Trejo, C., El viejo en la historia. Universidad de Chile. [En línea], disponible en: http://www.gerontologia.uchile.cl/docs/viejo. htm [Consultado el 7 de febrero de 2012]. 